\title{
Deletion of Sema4D gene reduces intimal neovascularization and plaque growth in apolipoprotein E-deficient mice
}

\author{
KAZUNORI YUKAWA ${ }^{1}$, TETSUJI TANAKA ${ }^{2}$, MASANORI KISHINO $^{3}$, KENJI YOSHIDA ${ }^{1}$, NORIKO TAKEUCHI ${ }^{1}$, \\ TAKUJI ITO $^{1}$, HYOTA TAKAMATSU ${ }^{4}$, HITOSHI KIKUTANI ${ }^{5}$ and ATSUSHI KUMANOGOH $^{4}$ \\ ${ }^{1}$ Department of Physiology, Faculty of Pharmacy, Meijo University, 150 Yagotoyama, Tempaku-ku, Nagoya 468-8503; \\ Departments of ${ }^{2}$ Obstetrics and Gynecology; ${ }^{3}$ Internal Medicine, Wakayama Medical University, 811-1 Kimiidera, \\ Wakayama 641-8509; Departments of ${ }^{4}$ Immunopathology; ${ }^{5}$ Molecular Immunology, Research Institute for \\ Microbial Diseases, Osaka University, 3-1 Yamada-oka, Suita, Osaka 565-0871, Japan
}

Received March 3, 2010; Accepted April 27, 2010

DOI: 10.3892/ijmm_00000432

\begin{abstract}
Neovascularization occurring in atherosclerotic plaque leads to acceleration of plaque growth through increased leukocyte infiltration and reactive oxygen species (ROS) production. Sema4D (CD100), a class IV semaphorin, not only plays a crucial role in axon guidance but also functions in the neovascularization process of tumor growth. To clarify the roles of Sema4D in the progression of atherosclerosis and neovascularization of atherosclerotic plaque, we analyzed the effect of Sema4D gene deletion from apolipoprotein E (ApoE)deficient mice in the development of atherosclerosis. Lipid staining demonstrated significant decreases in plaque areas in the aortas of 6-month-old Sema4D ${ }^{-/-} \mathrm{ApoE}^{-/-}$mice compared with 6-month-old ApoE-/- mice. Thus, the Sema4D gene knockout in ApoE-deficient mice was found to slow the progression of atherosclerosis. Immunohistochemical analyses confirmed the expression of Sema4D protein in infiltrating lymphoid cells in atherosclerotic plaque and plexin-B1 receptor in neovascular endothelial cells within the plaque. Furthermore, there were significant decreases in the degree of neovascularization in the plaque areas of Sema4D ${ }^{-/} \mathrm{ApoE}^{-/-}$mice compared with $\mathrm{ApoE}^{-/-}$ mice as revealed by both isolectin $\mathrm{B} 4$ and CD31 staining. The number of infiltrating macrophages in Sema4 $\mathrm{D}^{-/-} \mathrm{ApoE}^{-/}$ mice plaques was also significantly less than those in $\mathrm{ApoE}^{-/}$ mice. These findings suggest that Sema4D is involved in the progression phase of atherosclerosis by accelerating intimal neovascularization, resulting in enhanced macrophage infiltration in atherosclerotic plaques.
\end{abstract}

Correspondence to: Dr Kazunori Yukawa, Department of Physiology, Faculty of Pharmacy, Meijo University, 150 Yagotoyama, Tempaku-ku, Nagoya 468-8503, Japan

E-mail:kyukawa@ccmfs.meijo-u.ac.jp

Key words: semaphorin, atherosclerosis, neovascularization

\section{Introduction}

Neovascularization not only occurs in the formation stage of highly branched, tree-like tubular networks of blood vessels during development but also in physiological tissue remodeling in adults and the recovery phase subsequent to pathological tissue injury (1). Neovascularization has also been shown to occur in atherosclerotic plaques of human aorta and coronary arteries $(1,2)$. These neovessels originally derive from the adventitial vasa vasorum and nourish thickened atherosclerotic intimal growth (3). Thus, it is a widely accepted hypothesis that neovascularization is one of the major causes of atherosclerotic plaque growth and destabilization (4). Many experiments have suggested the mechanism by which neovascularization promotes atheroma development (5). The strong correlation between the vasa vasorum density and number of mononuclear cells infiltrating the plaque indicates that neovascularization functions as a crucial entry site for leukocyte invasion into atherosclerotic plaque $(6,7)$. Hemorrhaging from plaque neovessels aids blood lipid deposit in the lipid core of atheroma leading to further expansion of the plaque (8). Inhibition of plaque growth through decreased neovascularization in atherosclerosis-prone apolipoprotein E-deficient $\left(\mathrm{ApoE}^{-/-}\right)$mice with angiogenesis inhibitors such as angiostatin or TNP-470 indicates the functional importance of microvessel growth in the progression of atherogenesis $(7,9)$. Furthermore, neovessels in atheroma are thought to exacerbate atherosclerosis by increasing the intraplaque secretion of metalloproteinase from blood, leading to plaque rupture and thrombus formation (10).

Atherosclerosis is an inflammatory disease in which the immune system plays a major role during disease progression (11). The cell surface molecules CD40 and CD40 ligand (CD40L or CD154) are expressed in macrophages and T cells, respectively $(12,13)$. CD40 ligation involving interaction between CD40 and CD40L on intraplaque cells propagates inflammatory activation by inducing the secretion of proteases and pro-inflammatory mediators (12). Blocking of CD40 ligation and disruption of the gene encoding CD40L respectively reduce atherosclerotic plaques in atherosclerosisprone mice $(14,15)$. Moreover, stimulation of immune cells with antibodies against CD40 induces the expression of 
Sema4D (CD100), a member of the class IV semaphorin family (16). Semaphorins were initially identified as axon guidance molecules playing major roles in the determination of the axonal growth direction during the process of neuronal development (17). Later studies demonstrated various roles of semaphorins in, for example, the immune response, angiogenesis and epithelial morphogenesis (18). Thus, through secretion of soluble Sema4D by proteolytic cleavage of Sema4D extracellular domain from $\mathrm{T}$ cell surfaces during mutual immune cell activation mediated by CD40 ligation, Sema4D may exert certain effects on cells residing in atherosclerotic plaques after intraplaque secretion (19-21). Lymphocytes, macrophages, endothelial cells and platelets residing in plaques have a receptor for Sema4D on their membrane surface, namely, plexin-B1 (19-21). Sema4D has pro-angiogenic activity on endothelial cells in vitro and in vivo $(22,23)$. Even under pathological conditions, high expression levels of Sema4D in several squamous cell carcinomas suggest a critical role in tumor-induced angiogenesis in vivo (24). Thus, Sema4D may modulate plaque growth by acting during the neovascularization process occurring in atheroma. By deleting the Sema4D gene in atherosclerosis-prone ApoE ${ }^{-/-}$mice, we propose that Sema4D promotes intimal neovascularization during plaque growth.

\section{Materials and methods}

Mice. Sema4D $/ /$ mice under a C57BL/6J background were generated using the homologous recombination method with ES cells as previously reported (25). $\mathrm{ApoE}^{-/-}$mice (26) in a C57BL/6J background were obtained from The Jackson Laboratory (Bar Harbor, ME). Their progeny were bred to gain mice deficient in both Sema4D and ApoE. After weaning, mice were fed a normal diet. Animals were housed in the animal facilities of Wakayama Medical University and all experimental protocols were approved by the institutional Animal Ethics Review Committee.

Tissue processing. Mice were sacrificed at 6 months of age. The aorta was perfused for 3 min through a 21 gauge needle inserted into the left ventricular apex using phosphate-buffered saline (PBS) and then for another 3 min with $10 \%$ phosphatebuffered formalin. The aortic arch with its main branch points (branchiocephalic trunk, left common carotid artery and left subclavian artery) as well as the thoracic and abdominal aorta were excised and fixed in $10 \%$ phosphate-buffered formalin. The aorta was then stained with Sudan IV (Sigma-Aldrich, St. Louis, MO) and the percentage of lipid plaque area to total aortic area was quantified using Image J Software (Wayne Rasband, NIH, Bethesda, MD) as previously described (27).

Immunohistochemistry and morphometry. The aortic arch excised from anesthetized mice was fixed in $10 \%$ phosphatebuffered formalin. All vessels were embedded longitudinally in paraffin and cut into $4-\mu \mathrm{m}$ serial sections. Sections were immunolabeled with anti-mouse Sema4D antibody (Medical and Biological Laboratories Co., Ltd. Nagoya, Japan) and anti-mouse CD11b antibody (Serotec, Oxford, UK) to detect macrophages, and anti-mouse CD31 antibody (BD, Franklin Lakes, NJ) to stain endothelial cells. They were subsequently incubated with dextran polymer conjugated with secondary antibodies and peroxidase (DakoCytomation, Kyoto, Japan). To detect neovascularization (28), sections were pretreated with $1 \mathrm{mg} / \mathrm{ml}$ protease XIV (Sigma-Aldrich) for $15 \mathrm{~min}$ at room temperature and incubated for $1 \mathrm{~h}$ at room temperature with $7.5 \mathrm{mg} / \mathrm{ml}$ isolectin B4 from Bandeiraea simpilicifolia conjugated with fluorescein (Sigma-Aldrich). For double immunofluorescence analysis, tissue sections were incubated with anti-mouse CD31 antibody (BD) and anti-plexin-B1 antibody (Santa Cruz Biotechnology, Inc., Santa Cruz, CA). They were then incubated with Alexa-fluor 488 goat anti-rat IgG antibody (Molecular Probes, Eugene, OR) and Alexa-fluor 594 goat anti-rabbit IgG antibody (Molecular Probes) for fluorescent microscopic observation.

The degree of neovascularization was determined as a percentage calculated by dividing the isolectin B4 or CD31positive area by the respective plaque area using the Image-J morphometry system (Wayne Rasband). The relative area of atherosclerotic plaque positive for infiltrating macrophages was determined by dividing the CD11b-positive area by the total plaque area using Image-J software (Wayne Rasband).

Statistical analysis. Data are expressed as means \pm SEM. ApoE ${ }^{-/}$Sema4D ${ }^{-/-}$mice were compared with $\mathrm{ApoE}^{-/-}$mice using Student's t-test. Data were considered statistically significant at $\mathrm{p}<0.05$.

\section{Results}

Delayed development of atherosclerotic plaques in ApoE-1Sema $4 D^{-/}$mice. To analyze the effect of Sema4D gene deletion in ApoE-deficient mice on atherosclerosis development, sudanophilic staining of aortas dissected from both $\mathrm{ApoE}^{-/-}$and ApoE ${ }^{-/-}$Sema4 $\mathrm{D}^{-/-}$mice was performed. The results revealed a significant delay in atherosclerotic plaque development in aortic regions of 6-month-old ApoE ${ }^{-/}$Sema4D ${ }^{-/-}$mice compared with 6-month-old ApoE ${ }^{-/-}$mice (Fig. 1A). As shown in Fig. 1B, quantitative measurement of atherosclerotic plaque areas demonstrated that the mean percentage of sudanophilic areas to the whole aortic region in 6-month-old $\mathrm{ApoE}^{-/} \mathrm{Sema}_{4} \mathrm{D}^{-/-}$mice was significantly smaller than that in 6-month-old $\mathrm{ApoE}^{-/-}$mice (ApoE ${ }^{-/-}$Sema4D ${ }^{-/-}$mice, $15.70 \pm 2.29 \%$ vs. ApoE ${ }^{-/-}$mice, $23.72 \pm 2.57 \% ; \mathrm{P}<0.05, \mathrm{n}=5$ for each group).

Sema4D expressed in infiltrating lymphoid cells and plexin-B1 in endothelial cells. Immunohistochemistry to confirm the expression of Sema4D in atherosclerotic plaque showed the localization of Sema4D protein in infiltrating lymphoid cells as shown in Fig. 1C-a. To determine the expression pattern of plexin-B1, a receptor of Sema4D in atherosclerotic plaque, double immunofluorescence studies against CD31, an endothelial marker, and plexin-B1 were performed on plaque areas of atherosclerotic regions. The results demonstrated an overlapping pattern of CD31 (green) and plexin-B1 (red) in plaque areas (Fig. 1C-c and d), indicating plexin-B1 expression on endothelial cells of new vessels growing in the plaques.

Less neovascularization in ApoE $E^{-/}$Sema4D $D^{-/}$plaques. To study new vessel formation in the atherosclerotic plaques, isolectin B4 staining to detect neovascularization was initially employed 


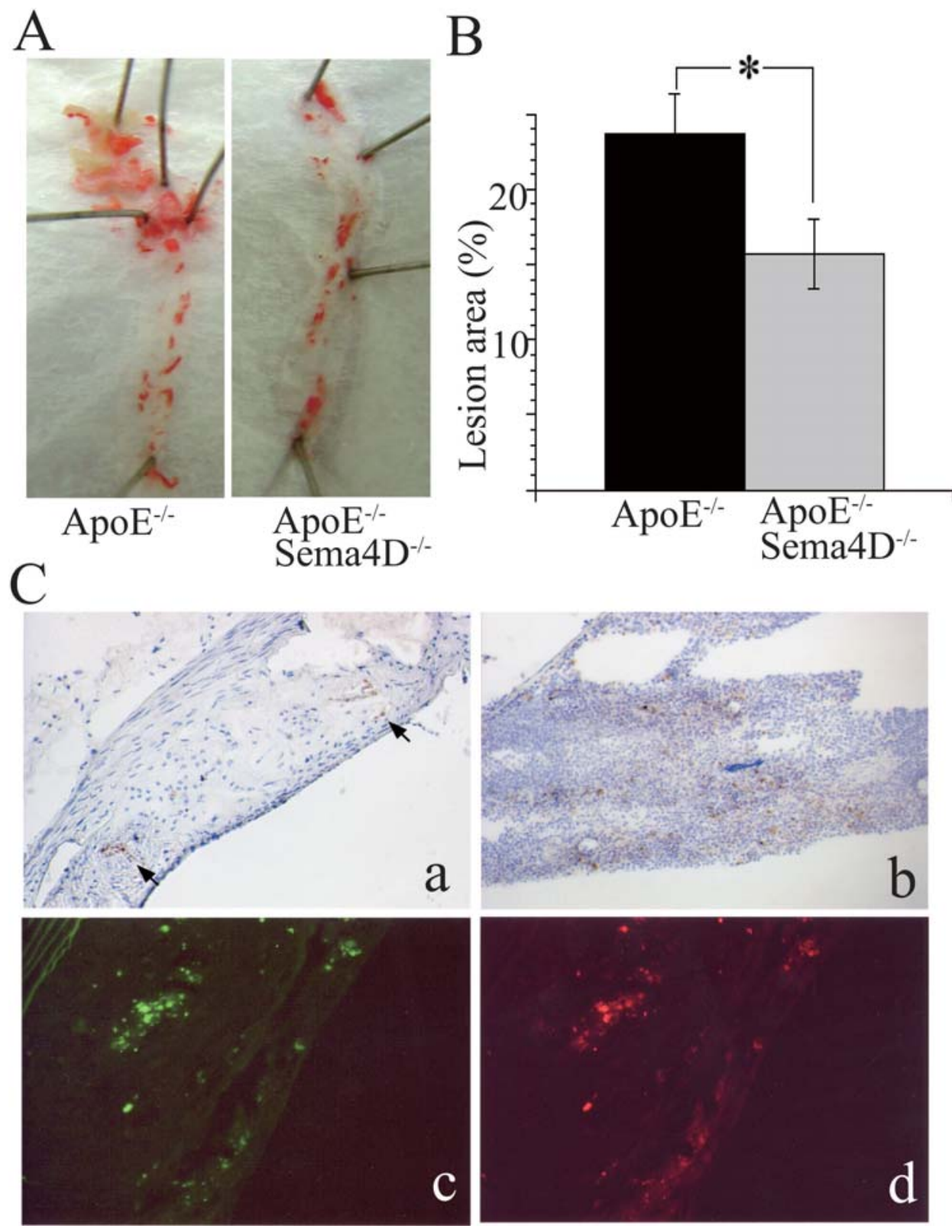

Figure 1. Delayed development of atherosclerotic plaques in $\mathrm{ApoE}^{-/}-\mathrm{Sema}_{4} \mathrm{D}^{-/}$mice. (A) Sudanophilic staining of aorta disclosed a significant delay in atherosclerotic plaque development in 6-month-old $\mathrm{ApoE}^{-/-}$Sema4 $\mathrm{D}^{-/-}$mice. (B) The sudanophilic area was significantly smaller in $6-\mathrm{month}-\mathrm{old}$ ApoE ${ }^{-/}$Sema4D ${ }^{-/-}$ atherosclerotic plaques compared with 6-month-old $\mathrm{ApoE}^{-/-}$plaques $\left(\mathrm{n}=5\right.$ for each group, $\left.{ }^{*} \mathrm{p}<0.05\right)$. (C) Antibodies against Sema4D which bound to lymphocytes in mouse spleen (brown in b) stained infiltrating lymphoid cells in atherosclerotic plaque (brown; arrows in a). Double immunofluorescence analyses revealed that CD31 staining of endothelial cells (green in c) precisely overlapped with the localization of plexin-B1 (red in d), indicating plexin-B1 expression in endothelial cells in atherosclerotic plaques.

with both 6-month-old ApoE $\mathrm{E}^{-/-}$and 6-month-old ApoE $\mathrm{E}^{-1-}$ Sema4D ${ }^{-/}$plaques. The results revealed that the percentage of isolectin $\mathrm{B} 4$ positive staining in the ApoE ${ }^{-/-} \mathrm{Sema}_{4} \mathrm{D}^{-/-}$plaques was significantly less than in the ApoE $\mathrm{E}^{-/-}$plaques $\left(\mathrm{ApoE}^{-/-}\right.$ Sema4D ${ }^{-/}$mice, $0.34 \pm 0.15 \%$ vs. ApoE ${ }^{-/}$mice, $3.04 \pm 1.03 \%$; $\mathrm{P}<0.05, \mathrm{n}=7$ for each group, Fig. $2 \mathrm{~A}$ and $\mathrm{B})$. Immunohistochemistry using antibodies against CD31 also confirmed that CD31 positive areas were significantly less in 6-month-old $\mathrm{ApoE}^{-/-}$Sema4D ${ }^{-/-}$plaques compared with 6-month-old ApoE ${ }^{-/-}$ plaques (ApoE ${ }^{-/}$Sema4D ${ }^{-/-}$mice, $0.49 \pm 0.14 \%$ vs. ApoE $E^{-/-}$mice, $3.96 \pm 0.81 \% ; \mathrm{P}<0.05, \mathrm{n}=7$ for each group, Fig. $2 \mathrm{C}$ and $\mathrm{D})$, underscoring poor neovascularization in Sema4D-deficient plaques.
Less macrophage infiltration in ApoE $E^{--}$Sema4 $D^{-/-}$plaques. Macrophage infiltration in the atherosclerotic plaques may originate from monocytes circulating in neovessels formed in the plaques $(6,7)$. To examine whether there was less macrophage infiltration in ApoE ${ }^{-/}$Sema4D $\mathrm{D}^{-/}$plaques, immunohistochemistry with F4/80 antibodies against macrophages was performed on plaques of 6-month-old $\mathrm{ApoE}^{-/-}$and 6-month-old ApoE ${ }^{-/}$Sema4D ${ }^{-/-}$mice. As a result, the degree of macrophage infiltration was shown to be significantly lower in 6-monthold $\mathrm{ApoE}^{-/-}$Sema4D $\mathrm{D}^{-/-}$plaques compared with 6-month-old ApoE $^{-/-}$plaques (ApoE $E^{-/-}$Sema4D $D^{-/-}$mice, $3.90 \pm 0.97 \%$ vs. $\mathrm{ApoE}^{-/-}$mice, $11.58 \pm 2.78 \% ; \mathrm{P}<0.05, \mathrm{n}=7$ for each group, Fig. 3A and B). 

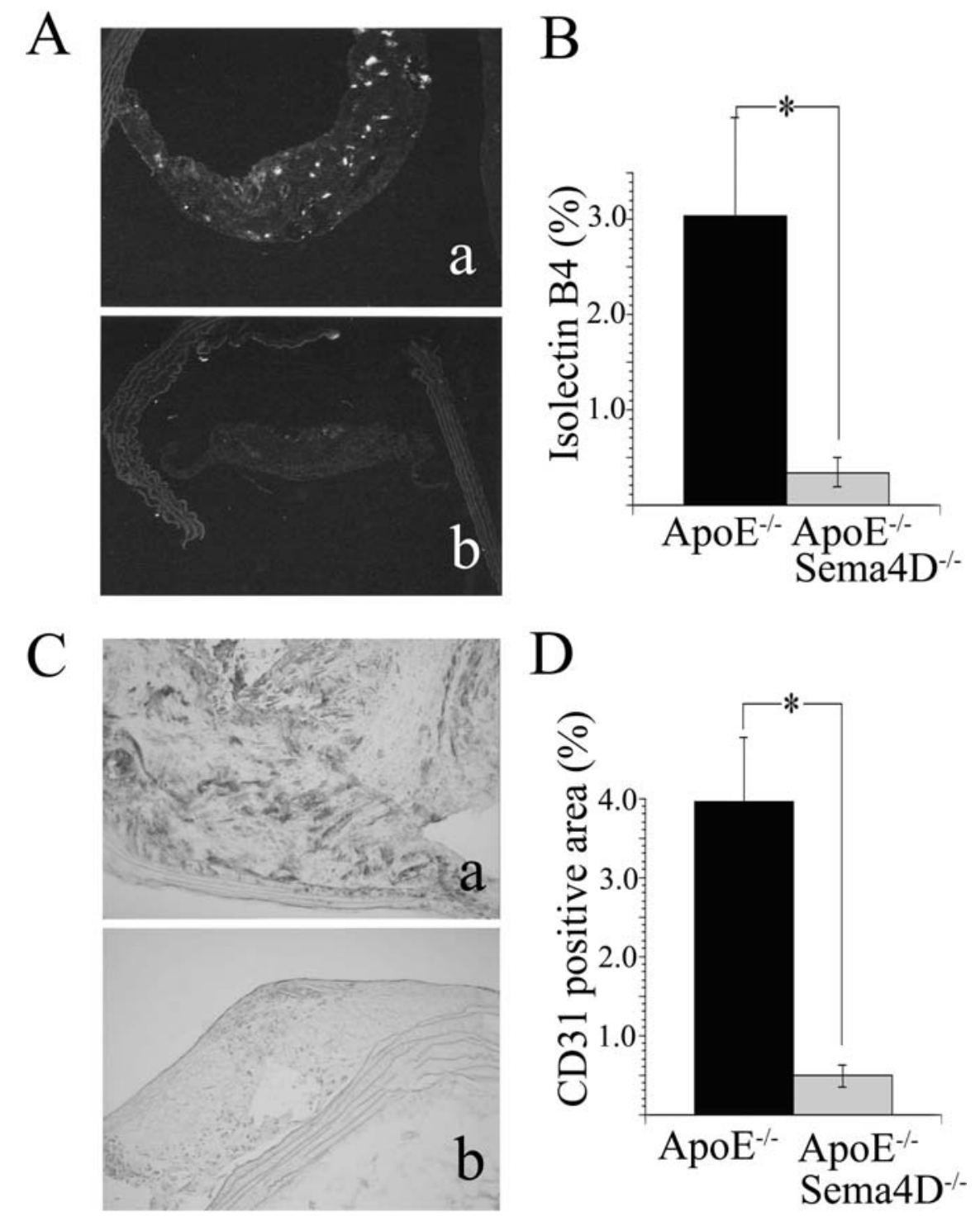

Figure 2. Reduced neovascularization in $\mathrm{ApoE}^{-/}-\mathrm{Sema}_{4} \mathrm{D}^{-/-}$plaques. (A) Neovascularization visualized by isolectin $\mathrm{B} 4 \mathrm{staining}$ in $\mathrm{ApoE} \mathrm{E}^{-/-} \mathrm{Sema} 4 \mathrm{D}^{-/-}$plaques $(\mathrm{b})$ appeared to be less than that in $\mathrm{ApoE}^{-/}$plaques (a). (B) Statistical analyses revealed that the isolectin $\mathrm{B} 4$ positive area in 6-month-old ApoE ${ }^{-/}$Sema4 $\mathrm{D}^{-/-}$plaques was significantly smaller than that in 6-month-old ApoE ${ }^{-/-}$plaques, indicating poor neovascularization in Sema4D-deficient plaques ( $\mathrm{n}=7$ for each group,

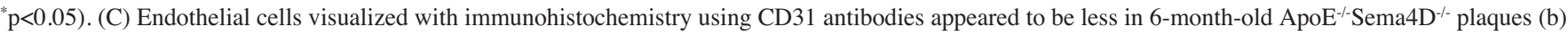
compared with 6-month-old ApoE ${ }^{-/-}$plaques (a). (D) Statistical analyses showed that CD31 positive areas were significantly less in 6-month-old ApoE ${ }^{-/-}$ Sema4 ${ }^{-/-}$plaques compared with 6-month-old ApoE ${ }^{-/}$plaques, indicating poor microvessels in Sema4D-deficient plaques $\left(\mathrm{n}=7\right.$ for each group, ${ }^{*} \mathrm{p}<0.05$ ).

\section{Discussion}

Our study revealed that deletion of the Sema4D gene in $\mathrm{ApoE}^{-1-}$ mice induced significant retardation in atheroma growth, reduction in intimal neovascularization and a decrease in macrophage infiltration in the plaques. Accordingly, our data suggest that Sema4D, secreted into atheroma plaques from the $\mathrm{T}$ cell surface as a result of proteolytic cleavage, facilitates plaque growth by promoting neovascularization through induction of endothelial cell migration.

Our finding that deletion of the Sema4D gene from $\mathrm{ApoE}^{-1-}$ mice led to significant retardation in plaque growth is comparable with the phenotype of atherosclerosis-prone LDL receptor (LDLR) knockout mice in which the Sema4D gene was also deleted (29). Although in this previous study, the mice were maintained using a high fat diet different from the normal diet employed here, both studies obtained consistent data supporting the promotion of atherosclerosis development by Sema4D. It was proposed that deletion of the Sema4D gene from $\mathrm{LDLR}^{-/-}$mice lessens platelet function leading to retarded atheroma growth (29). Alhough knockout of another platelet related molecule, $\alpha_{\mathrm{IIb}} \beta_{3}$, results in a stronger platelet inhibitory effect than Sema4D knockout, the inhibitory effects of deletion of both genes on atherosclerosis are the same $(29,30)$. This indicates that Sema4D affects the function of other cellular factors in addition to platelets.

Many experiments have supported the concept that intimal neovascularization promotes the growth of atheroma plaque $(5,7,9)$. Factors such as VEGF, IL-8 and Cox-2 play crucial roles in facilitating intimal neovascularization (31-34). Sema4D 

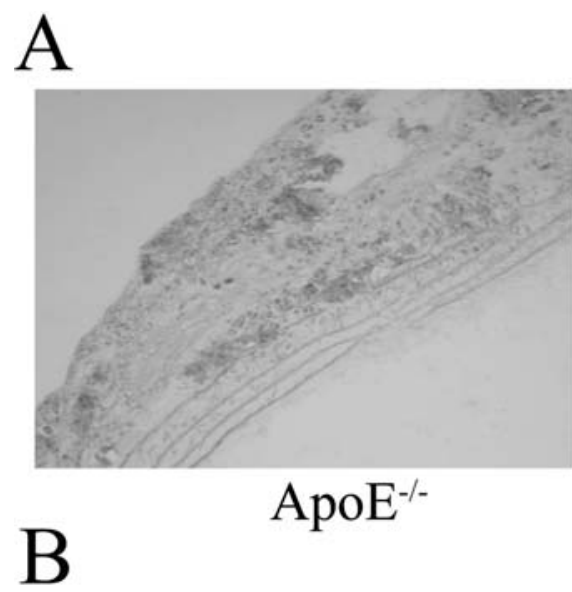

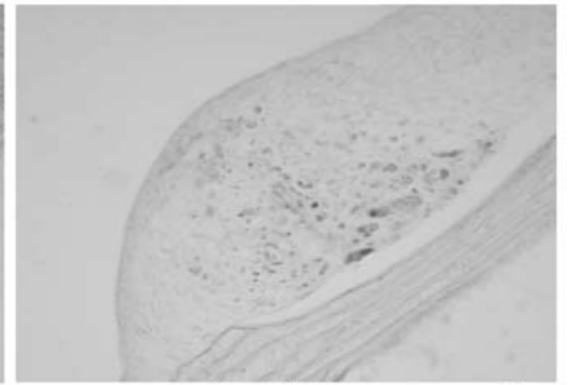

$\mathrm{ApoE}^{-/-}$Sema4D $/-$

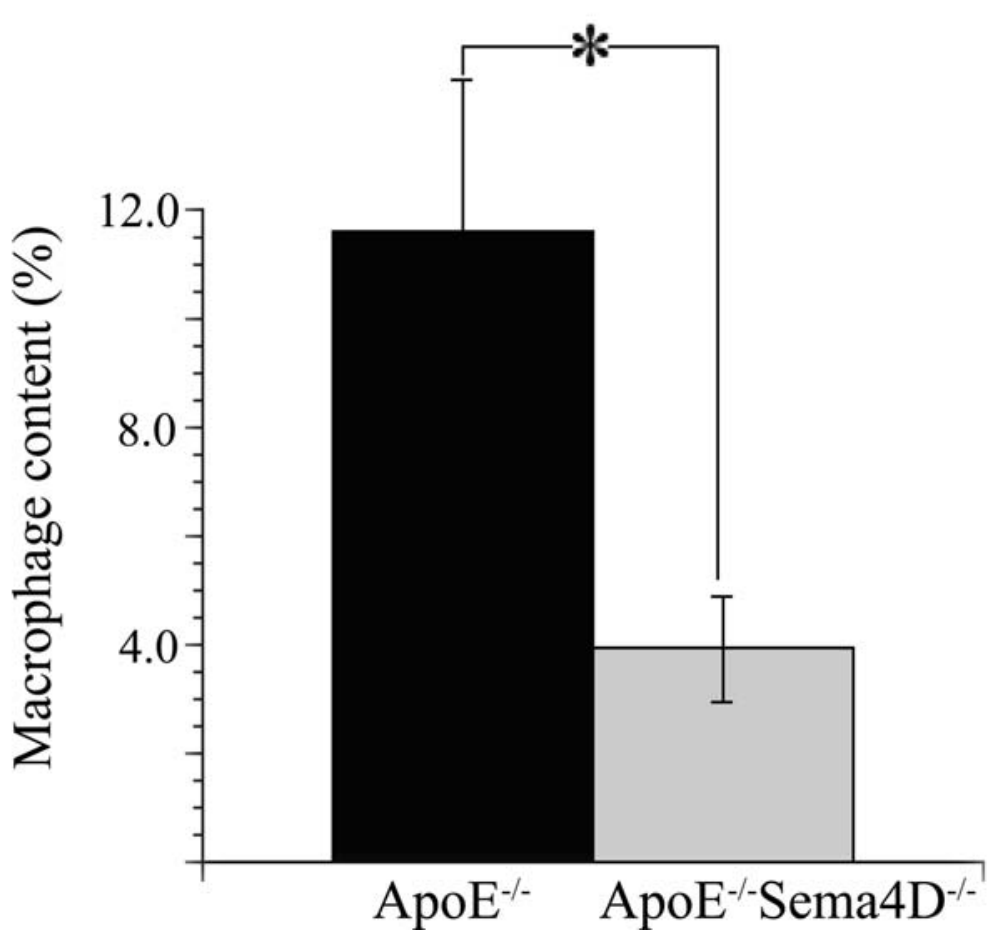

Figure 3. Poor macrophage infiltration in Sema4D-deficient plaques. (A) Macrophage infiltration revealed by immunohistochemistry with F4/80 antibodies appeared to be less in 6-month-old $\mathrm{ApoE}^{-/-} \mathrm{Sema}_{4} \mathrm{D}^{-/}$plaques than 6-month-old ApoE ${ }^{-/-}$plaques. (B) Statistical analyses disclosed that the macrophage content in 6-month-old $\mathrm{ApoE}^{-/-} \mathrm{Sema}^{-/-}$plaques was significantly less than in 6-month-old $\mathrm{ApoE}^{-/-}$plaques $\left(\mathrm{n}=7 \mathrm{for}\right.$ each group, $\left.{ }^{*} \mathrm{p}<0.05\right)$.

displays proangiogenic activity comparable with VEGF and FGF in both in vitro and in vivo assays $(22,23)$. However, the proangiogenic activity of Sema4D is not thought to be mediated by the up-regulation of VEGF or angiopoietins (22). Determining the specific action exerted by Sema4D in intimal neovascularization, during which factors such as VEGF display major effects, is therefore important. A study of tumor-induced angiogenesis showed that Sema4D works as a directional cue for endothelial cell migration, thus leading to regional neovascularization rather than endothelial cell growth promotion exerted by cytokines such as VEGF (24). It is also known that neovascularization shows regional preference, occurring in atherosclerotic plaque $(7,35)$. Thus, distinct from VEGF, Sema4D may control regional neovascularization by guiding endothelial cell migration into atheroma. Sema4D exerts proangiogenic activity by binding the plexin-B 1 receptor expressed on the endothelial cell surface $(22,23)$. Sema4D ligation to plexin-B1 in endothelial cells is integrated not with the rho-rho kinase pathway but with Met receptor- mediated signal transduction machinery $(22,23)$. Interestingly, R-Ras, the activity of which is down-regulated during signal transduction of Sem4D ligation to plexin-B1, also functions to inhibit intimal hyperplasia and tumor angiogenesis (36). This indicates that after binding to plexin-B1 on endothelial cells Sema4D induces intimal growth and angiogenesis by down-regulating R-Ras activity, supporting the present findings. Thus, we propose that Sema4D cleaved and shed from $\mathrm{T}$ lymphocytes infiltrating developing atherosclerotic plaque contributes to further atheroma growth by inducing regional neovessel formation as a cue for endothelial cell migration into the plaques. This then results in an increase in macrophage invasion into the plaque from newly produced vessels.

\section{Acknowledgements}

We are grateful to K. Kubota, M. Ichinose, T. Ueyama, S. Yukawa and E. Yukawa for their encouragement and support. This study was partly supported by Grants-in-Aid for 
Scientific Research from the Ministry of Education, Science, Sports and Culture, Japan.

\section{References}

1. Carmeliet P: Angiogenesis in health and disease. Nature Med 9: 653-660, 2003

2. Zhang Y, Cliff WJ, Schoefl GI and Higgins G: Immunohistochemical study of intimal microvessels in coronary atherosclerosis. Am J Pathol 143: 164-172, 1993.

3. Kumamoto M, Nakashima $Y$ and Sueishi K: Intimal neovascularization in human coronary atherosclerosis: Its origin and pathophysiological significance. Hum Pathol 26: 450-456, 1995.

4. Barger AC, Beeuwkes R 3rd, Lainey LL and Silverman KJ: Hypothesis: vasa vasorum and neovascularization of human coronary arteries. A possible role in the pathophysiology of atherosclerosis. N Engl J Med 310: 175-177, 1984.

5. Moreno PR, Purushothaman KR, Sirol M, Levy AP and Fuster V: Neovascularization in human atherosclerosis. Circulation 113: 2245-2252, 2006.

6. O'Brien ER, Garvin MR, Dev R, Stewart DK, Hinohara T, Simpson JB and Schwartz SM: Angiogenesis in human coronary atherosclerosis plaques. Am J Pathol 145: 883-894, 1994.

7. Moulton KS, Vakili K, Zurakowski D, Soliman M, Butterfield C, Sylvin E, Lo K-M, Gillies S, Javaherian K and Folkman J Inhibition of plaque neovascularization reduces macrophage accumulation and progression of advanced atherosclerosis. Proc Natl Acad Sci USA 100: 4736-4741, 2003

8. Kolodgie FD, Gold HK, Burke AP, Fowler DR, Kruth HS, Weber DK, Farb A, Guerrero LJ, Hayase M, Kutys R, Narula J, Finn AV and Virmani R: Intraplaque hemorrhage and progression of coronary atheroma. N Engl J Med 349: 2316-2325, 2003.

9. Moulton KS, Heller E, Konerding MA, Flynn E, Palinski W and Folkman J: Angiogenesis inhibitors endostatin or TNP-470 reduce intimal neovascularization and plaque growth in apolipoprotein E-deficient mice. Circulation 99: 1726-1732, 1999.

10. Jonsson-Rylander AC, Nilsson T, Fritsche-Danielson R, Hammarstrom A, Behrendt M, Andersson JO, Lindgren K, Andersson AK, Wallbrandt P, Rosengren B, Brodin P, Thelin A, Westin A, Hurt-Camejo E and Lee-Sogaard CH: Role of ADAMTS-1 in atherosclerosis: remodeling of carotid artery, immunohistochemistry, and proteolysis of versican. Arterioscler Thromb Vasc Biol 25: 180-185, 2005.

11. Hansson GK and Libby P: The immune response in atherosclerosis: a double-edged sword. Nat Rev Immunol 6: 508-519, 2006.

12. Mach F, Schönbeck U, Bonnefoy JY, Pober JS and Libby P. Activation of monocyte/macrophage functions related to acute atheroma complication by ligation of CD40. Induction of collagenase, stromelysin, and tissue factor. Circulation 96: 396-399, 1997

13. Mach F, Schönbeck U, Sukhova GK, Bourcier T, Bonnefoy JY, Pober JS and Libby P: Functional CD40 ligand is expressed on human vascular endothelial cells, smooth muscle cells, and macrophages: implications for CD40-CD40 ligand signaling in atherosclerosis. Proc Natl Acad Sci USA 94: 1931-1936, 1997.

14. Mach F, Schönbeck U, Sukhova GK, Atkinson E and Libby P: Reduction of atherosclerosis in mice by inhibition of CD40 signaling. Nature 394: 200-203, 1998.

15. Lutgens E, Gorelik L, Daemen MJ, deMuinck ED, Grewal IS, Koteliansky VE and Flavell RA: Requirement for CD154 in the progression of atherosclerosis. Nat Med 11: 1313-1316, 1999.

16. Kumanogoh A, Watanabe C, Lee I, Wang X, Shi W, Araki H, Hirata H, Iwahori K, Uchida J, Yasui T, Matsumoto M, Yoshida K, Yakura H, Pan C, Parnes JR and Kikutani H: Identification of CD72 as a lymphocyte receptor for the class IV semaphorin CD100: a novel mechanism for regulating B cell signaling. Immunity 13: 621-631, 2000.

17. Raper JA: Semaphorins and their receptors in vertebrates and invertebrates. Curr Opin Neurobiol 10: 88-94, 2000.

18. Kruger RP, Aurandt J and Guan KL: Semaphorins command cells to move. Nat Rev Mol Cell Biol 6: 789-800, 2005.

19. Basile JR, Afkhami T and Gutkind JS: Semaphorin 4D/Plexin-B1 induces endothelial cell migration through the activation of PYK2, src, and the phosphatidylinositol 3-kinase-Akt pathway. Mol Cell Biol 25: 6889-6898, 2005.
20. Delaire S, Billard C, Tordjman R, Chedotal A, Elhabazi A Bensussan A and Boumsell L: Biological activity of soluble CD100. II. Soluble CD100, similarly to H-SemaIII, inhibits immune cell migration. J Immunol 166: 4348-4354, 2001.

21. Chabbert-de Ponnat I, Marie-Cardine A, Pasterkamp RJ, Schiavon V, Tamagnone L, Thomasset N, Bensussan A and Boumsell L: Soluble CD100 functions on human monocytes and immature dendritic cells require plexin $\mathrm{C} 1$ and plexin $\mathrm{B} 1$, respectively. Int Immunol 17: 439-447, 2005

22. Conrotto P, Valdembri D, Corso S, Serini G, Tamagnone L, Comoglio PM, Bussolino F and Giordano S: Sema4D induces angiogenesis through Met requirement by plexin B1. Blood 105: 4321-4329, 2005

23. Basil JR, Barac A, Zhu T, Guan KL and Gutkind JS: Class IV semaphorins promote angiogenesis by stimulating Rho-initiated pathways through plexin-B. Cancer Res 64: 5212-5224, 2004.

24. Basile JR, Castilho RM, Williams VP and Gutkind JS: Semaphorin 4D provides a link between axon guidance process and tumor-induced angiogenesis. Proc Natl Acad Sci USA 103: 9017-9022, 2006

25. Shi W, Kumanogoh A, Watanabe C, Uchida J, Wang X, Yasui T, Yukawa K, Ikawa M, Okabe M, Parnes JR, Yoshida K and Kikutani H: The class IV semaphorin CD100 plays nonredundant roles in the immune system: defective $B$ and $T$ cells activation in CD100-deficient mice. Immunity 13: 633-642, 2000.

26. Piedrahita JA, Zhang SH, Hagaman JR, Oliver PM and Maeda N: Generation of mice carrying a mutant apolipoprotein $\mathrm{E}$ gene inactivated by gene targeting in embryonic stem cells. Proc Natl Acad Sci USA 89: 4471-4475, 1992.

27. Dougherty A and Whitman SC: Quantification of atherosclerosis in mice. In: Methods in Molecular Biology, vol. 209: Transgenic Mouse Methods and Protocols. Hofker MH and van Deursen J (eds). Humana Press Inc., Totowa, pp293-309, 2002.

28. Lim KY, Ryan EA, Wong PKY and Yuen P-H: Studies on the pathology, especially brain hemorrhage and angioendotheliomas, induced by two new mos-containing viruses. J NeuroVirol 6: 106-120, 2000

29. Zhu L, Stalker TJ, Fong KP, Jiang H, Tran A, Crichton I, Lee EK, Neeves KB, Maloney SF, Kikutani H, Kumanogoh A, Pure E, Diamond SL and Brass LF: Disruption of Sema4D ameliorates platelet hypersensitivity in dyslipidemia and confers protection against the development of atherosclerosis. Arterioscler Thromb Vasc Biol 29: 1039-1045, 2009.

30. Massberg S, Schrzinger K, Lorenz M, Konrad I, Schulz C, Plesnila N, Kennerknecht E, Rudelius M, Sauer S, Braun S, Kremmer E, Emambokus NR, Frampton J and Gawaz M: Platelet adhesion via glycoprotein IIb integrin is critical for atheroprogression and focal cerebral ischemia: an in vivo study in mice lacking glycoprotein IIb. Circulation 112: 1180$1188,2005$.

31. Celletti FL, Waugh JM, Amabile PG, Brendolan A, Hilficker PR and Dake MD: Vascular endothelial growth factor enhances atherosclerotic plaque progression. Nat Med 7: 425-429, 2001.

32. Schönbeck U, Sukhova GK, Graber P, Coulter S and Libby P: Augmented expression of cyclooxygenase-2 in human atherosclerotic lesions. Am J Pathol 155: 1281-1291, 1999.

33. Simonini A, Moscucci M, Muller DW, Bates ER, Pagani FD, Burdick MD and Strieter RM: IL- 8 is an angiogenic factor in human coronary atherectomy tissue. Circulation 101: 1519-1526, 2000.

34. Bochkov VN, Philippova M, Oskolkova O, Kadl A, Furnkranz A, Karabeg E, Afonyushkin T, Gruber F, Breuss J, Minchenko A, Mechtcheriakova D, Hohensinner P, Rychli K, Wojta J, Resink T, Erne P, Binder BR and Leitinger N: Oxidized phospholipids stimulate angiogenesis via autocrine mechanisms, implicating a novel role for lipid oxidation in the evolution of atherosclerotic lesions. Circ Res 99: 900-908, 2006.

35. Moulton KS: Plaque angiogenesis and atherosclerosis. Curr Atheroscler Rep 3: 225-233, 2001.

36. Komatsu M and Ruoslahti E: R-Ras is a global regulator of vascular regeneration that suppresses intimal hyperplasia and tumor angiogenesis. Nat Med 11: 1346-1350, 2005. 